\title{
Brain reactivity and event - related potentials (ERPs) in patients with sleeping sickness
}

Sir,

It is well established that a disturbance of sleep - waking cycle characterizes patients with a meningoencephalitic stage of Gambian trypanosomiasis $[1,2,3]$. Meanwhile, no research has been done on central responsiveness and cognitive functions in this illness.

We recorded the late components ( $\mathrm{N} 2$ and $\mathrm{P} 3$ waves) of ERP (which are related to stimulus evaluation and decision making processes) and the contingent negative variation (which is linked both to attention and motivation) elicited by simple and paired auditory stimuli during a sensorimotor task in 16 patients at the meningoencephalitic stage of sleeping sickness. Data acquisition and analysis were done on an Apple II E microcomputer, with a sampling rate of $200 \mathrm{~Hz}$ [4].

The latency of N2 and P3 auditory ERP components and the reaction time were significantly increased, while the amplitude of the contingent negative variation and $\mathrm{N} 2$ wave were severely decreased in patients enfected with Trypanosome gambiense compared to control subjects.

Our finding in sleeping sickness are consistent not with those obtained from a sleeping subject, but with those obtained from a totally sleep-deprived subject. Indeed, and contrarily to sleeping, our patients showed no a great enhancement of the later ERP components. This could be related to the fact that the quality and the quantity of delta waves observed during waking on electroencephalographic recordings in sleeping sickness are not equivalent to the delta waves occurring in natural slow wave sleep. Our results are similar to those obtained by Gauthier and Gottesmann [5] in a group of normal men during waking after a total sleep deprivation. Indeed this situation increases the latency and decreases the amplitude of the later components of ERP. As it has been suggested by Gauthier and Gottesmann (i.e.) in humans after a total sleep deprivation, results ob- taind in the present study are probably the sign of a passive attitude in relation to the experimental situation (increase of reaction time) and a decrease of attention processes (decrease of contingent negative variation amplitude and of $\mathrm{N} 2$ auditory ERP component) related to the disturbance of sleep-waking cycle in patients at the meningoencephalitic stage of trypanosomiasis.

Hamon J.F.*, Gauthier P.**, Camara P.A.***, Arnaud C.** and Gottesmann C.**

* Laboratoire de Psychologie Expérimentale et Comparée U.N.S.A., Nice, France. ** Laboratoire de Psychophysiologie, Faculté des Sciences, Parc Valrose, Nice, France. *** Laboratoire de Physiologie Animale et de Psychophysiologie, Faculté des Sciences et Techniques d'Abidjan, Côte-d'Ivoire.

\section{References}

[1] Collomb A., Demarchi J., Miletto G.: Trypanosomiase humaine africaine. In Traité de Médecine, Paris, Masson, 268-350, 1958.

[2] Dumas M., GIRARD P.L.: Human African trypanosomiasis. In Vinken and Bruyn (Eds), Vol. 35, Handbook of Clinical Neurology. Infection of the nervous system, part 3, 67-83, 1978.

[3] Gallais P.: Etude électroencéphalographique de la trypanosomiase humaine africaine. Rev. Neurol., 85:95-104, 1951.

[4] Hamon J.F., Gauthier P., ARnaud C., GotTesMANN C.: Analyse micro-informatisée sur Apple II $E$ des potentiels liés à l'événement: premières applications en Afrique de l'ouest. Médecine d'Afrique Noire, 50 (2):245-248, 1990.

[5] GAUTHIER P., GOTTESMANN C.: Influence of total sleep deprivation on event-related potentials in man. Psychophysiology, 20:351-355, 1983. 